\title{
Aplicación de buenas prácticas ganaderas en una finca especializada en producción de leche, Usme, Cundinamarca, Colombia
}

\section{Application of good farming practice in a farm specialized in milk production, Usme, Cundinamarca, Colombia}

\begin{abstract}
Romero Hortúa Amalia Johanna ${ }^{1}$, Roa Vega María Ligia² y López Martínez Miguel Alberto ${ }^{3}$

${ }^{1}$ Médico Veterinaria Zootecnista. Universidad de los Llanos

2Zootecnista, Esp. MSc. Docente Universidad de los Llanos. ${ }^{3}$ Médico Veterinario. Finagrarios Ltda.
\end{abstract}

mroa@unillanos.edu.co

Recibido 05 de Marzo 2013, Aceptado 15 de Abril 2013

\section{RESUMEN}

El objetivo de este trabajo fue aplicar las buenas prácticas ganaderas en la Hacienda "Palo Negro" con el propósito de mejorar la calidad de la leche, enfatizando en la rutina de ordeño y las técnicas de bienestar animal. La finca está ubicada en la vereda "El Destino" en Usme, Cundinamarca, a 3.200 m.s.n.m., con una temperatura promedio de $12^{\circ} \mathrm{C}$; tiene un hato de 160 vacas lecheras Holstein puro, cuyo alimento básico son las gramíneas: raigrass (Lolium $s p$ ), falsa poa (Holcus lanatus), azul orchoro (Dactylis glomerata) y leguminosas: trébol rojo (Trifolium pratense) y blanco (Trifolium repens). La producción promedio diaria del hato es 16 litros de leche/vaca, se suministra un $\mathrm{kg}$ de suplemento concentrado por cinco litros de leche producida. Para iniciar el proceso de certificación de predio libre de brucelosis y tuberculosis, se tomaron muestras de sangre en la totalidad de los animales del hato, las cuales fueron enviadas al laboratorio, los resultados en estas dos pruebas fueron negativos. Con el fin de determinar la presencia de mastitis, se realizó la prueba de CMT (Test de Mastitis California) en la ubre de una muestra de 40 vacas antes de iniciar las buenas prácticas ganaderas y después de aplicarlas, haciendo evaluaciones cada mes. Con la aplicación de buenas prácticas ganaderas disminuyó de manera gradual en seis meses la incidencia de mastitis en las vacas de la finca "Palo Negra" de 78.8 a 
$58.5 \%$, lo cual indica que 34 vacas de las 160 respondieron a los tratamientos veterinarios, los cuales fueron aplicados rigurosamente. Igual situación se presentó en las unidades formadoras de colonias y recuento de células somáticas las cuales disminuyeron en seis meses de 625.000 Vs 11.680 (leche recién ordeñada) a 2'371.000 Vs 2'019.000 (leche almacenada en cantina).

Palabras clave: Ganado Holstein, mastitis, bienestar animal.

\section{ABSTRACT}

The objective of this work was to apply good livestock practices in the farm "Palo negro" with the purpose of improving the quality of milk, emphasizing the milking routine and techniques of animal welfare. The farm is located in the village of "El Destino" Usme, Cundinamarca, at 3.200 m.s.n.m., average temperature of $12^{\circ} \mathrm{C}$, this farm has 160 dairy cows Holstein grazing in: Lolium sp, Holcus lanatus, Dactylis glomerata and legumes: Trifolium pratense and Trifolium repens. The daily average production is 16 liters of milk/cow, one $\mathrm{kg}$ of concentrated supplement is supplied per five liters of milk produced. To start the certification process free property brucellosis and tuberculosis, blood samples were taken in all animals, which were sent to the laboratory, the results in these two tests were negative. To determine the presence of mastitis, CMT (Californian Mastitis Test) test conducted in the udder of a sample of 40 cows before starting the good practices and after their application, making evaluations every month. With the application of good practices gradually decreased in six months the incidence of mastitis in cows from the farm "Palo Negro" from 78.8 to $58.5 \%$, indicating that 34 of the 160 cows responded to veterinary treatments, which was applied rigorously. Same happened colony forming units and somatic cells count decreased in six months 625.000 vs 11.680 (recently milked milk) and 2'371.000 vs 2’019.000 (milk stored in canteen).

Keywords: Holstein cattle, mastitis, animal welfare. 


\section{INTRODUCCIÓN}

El consumidor, demanda de la industria agroalimentaria, la necesidad de que le oferten alimentos de origen animal de alta calidad e inocuidad destinados para su consumo, planteándole así un reto a los profesionales del sector pecuario, al exigirles mayores estándares de calidad dentro de la cadena productiva, y a su vez, la academia con el desarrollo de investigaciones y nuevas tecnologías, debe poner al servicio de este propósito todos los recursos con los que cuenta (MPS, 2006).

Se sabe que el ganadero de lechería, esgrime teorías como "el volumen es el que paga", pero, al no haber relación entre calidad y cantidad, finalmente el valor esperado por litro de leche, se ve afectado o castigado su pago. Por tanto, las condiciones higiénicas, sanitarias y composicionales de la leche son los factores más importantes en la determinación del precio. La calidad, hoy en día, es un término que se emplea frecuentemente en la mayoría de áreas del conocimiento, teniendo como fundamento las características que tienen las personas o los productos y que denotan cierto grado de categorización. En el caso de la leche, siendo ésta un producto de consumo masivo, la calidad debe ser un requisito primordial y constante. Al implementar las buenas prácticas ganaderas en una producción lechera, enfatizándose en el protocolo higiénico del ordeño, los frutos esperados serían el mejoramiento de la calidad de la leche, haciendo más productiva, sostenible y rentable la ganadería, al reducir el impacto económico del rechazo del producto, los bajos precios y los altos costos de asistencia y medicamentos veterinarios (Ramos et al., 2006). Por esto a través de este proyecto se propuso el establecimiento de buenas prácticas ganaderas (BPG) en la Hacienda "Palo Negro" que permitan alcanzar lo anteriormente planteado.

\section{CALIDAD DE LA LECHE BOVINA}

La calidad composicional de la leche bovina constituida por el contenido de sólidos totales, grasa y proteína, determina su valor nutricional y su aptitud como materia prima para el procesamiento, la cual varía en función de aspectos de tipo genético 
(inter-raciales e intra-raciales), fisiológico (edad, etapa de la lactancia y estado sanitario de las vacas) y ambiental (alimentación, clima y sistema de manejo). Desde el punto de vista de su valor nutricional, la leche bovina constituye una excelente fuente de proteínas (caseínas, lactoglobulinas, lactoalbúminas e inmunoglobulinas, entre otras), carbohidratos (lactosa), lípidos (triglicéridos y fosfolípidos), y minerales (calcio, fósforo, sodio, potasio y cloro), convirtiéndose en un alimento ideal para el ser humano en sus diferentes etapas de desarrollo y en un sustituto perfecto de la leche materna en lactantes (Novoa, 2005).

Para conseguir la inocuidad de la leche es necesario considerar su calidad higiénica que se refiere a la cantidad y tipo de bacterias presentes en la leche como consecuencia del manejo durante el ordeño, el almacenamiento y el transporte de la misma. La leche además de ser un medio nutritivo, es también un medio favorable desde el punto de vista físico para la multiplicación de los microorganismos y por ser un producto de origen animal sujeto a una gran diversidad de métodos de producción, se puede contaminar con un amplio espectro de microorganismos presentes en pezones, canal del pezón, superficies de la ubre, ubres mastíticas, agua contaminada utilizada en los sistemas de lavado y equipos de ordeño (Anda, 2007).

El concepto de inocuidad en la cadena agroalimentaria de la leche bovina, debe provenir de la implementación adecuada y estricta de planes y programas preventivos que garanticen la sanidad de los animales, la higiene de la leche y la salud pública del consumidor, minimizando el impacto de las enfermedades transmitidas por alimentos de origen lácteo y la incidencia de zoonosis. La calidad sanitaria se puede garantizar a través del establecimiento del registro único de vacunación (RUV) y de la inscripción de las explotaciones ganaderas en un programa de "hatos libres de brucelosis", y la calidad higiénica mediante la determinación del recuento total de bacterias (RTB). Para configurar un concepto amplio y pertinente de inocuidad en esta cadena agroalimentaria, se deben implementar en el ámbito de las explotaciones ganaderas programas de Buenas Prácticas Ganaderas (BPG) y Buenas Prácticas en el Empleo de Medicamentos 
Veterinarios (BPMV); así como Buenas Prácticas de Manufactura (BPM) y de Análisis de Peligros y Control de Puntos Críticos (HACCP) en las plantas pasteurizadoras y procesadoras de leche bovina, las cuales sumadas a un programa de identificación individual y único de los animales en las fincas y la rastreabilidad del producto a lo largo de la cadena agroalimentaria, garantizarán la calidad higiénico-sanitaria de la leche y los derivados lácteos (Ramos et al., 2006).

\section{PROCEDIMIENTO PARA DETERMINAR LA CALIDAD DE LA LECHE}

Para determinar si la leche proviene de cuartos afectados de mastitis se utiliza la prueba Californian Mastitis Test (CMT). A una muestra de leche de cada cuarto, se le adiciona el detergente alquil-aril-sulfonato de sodio que forma un gel en presencia de un alto número de células somáticas. La prueba puede determinar varios grados de afección, según la fuerza del gel formado. Para determinar la calidad sanitaria de la leche a nivel de tanque, se utiliza el recuento de células somáticas (neutrófilos, leucocitos, polimorfonucleares y células epiteliales). En los casos de mastitis se aumenta el número de leucocitos. En leche de tanque, un recuento de células somáticas menor de 400.000 células por $\mathrm{ml}$ se considera bajo, mientras que un recuento mayor de 700.000 células por $\mathrm{ml}$ se considera alto, indicando que la leche proviene de hatos con alta incidencia de mastitis. El recuento de células somáticas también se aplica a leche de animales individuales, pero es necesario tener en cuenta que las células somáticas se ven aumentadas por causas diferentes a la mastitis, como al inicio y final de la lactancia, o con el estrés de los animales, aunque el incremento en estos casos no es tan pronunciado como en la mastitis. El aumento de células somáticas también está relacionado con mayor actividad proteolítica y lipolítica que causa cambios en la calidad sensorial de la leche y sus derivados. También es importante que la leche esté libre de residuos, adulterantes, desinfectantes y de medicamentos principalmente de antibióticos, por lo cual la leche de animales que reciben tratamientos con antibióticos no debe destinarse al consumo humano. Para determinar la presencia de antibióticos e inhibidores de crecimiento bacteriano en leche se utilizan pruebas basadas en la formación de un halo de inhibición o en el 
desarrollo de acidez por una bacteria específica en un sustrato especial; uno de las pruebas más conocidas es el Delvo-test (Rodríguez, 2007).

También existen pruebas específicas que reconocen ciertas estructuras de algunos antibióticos como es el caso de los beta-lactámicos. Se debe controlar la presencia de adulterantes en leche utilizados para disimular la mala calidad. Es importante identificar la presencia de formol, hipocloritos, compuestos de amonio cuaternario, peróxido de hidrógeno, sal, azúcar, féculas y agua adicionada en la leche. Las leches que resulten positivas a estos adulterantes deben ser rechazadas. La leche también debe estar libre de micotoxinas, las cuales provienen de los alimentos contaminados con moho, suministrados a los animales (Anda, 2007).

La leche recién ordeñada procedente de vacas sanas contiene aproximadamente 15.000 UFC/ml en condiciones normales, pero se admiten hasta $25.000 \mathrm{UFC} / \mathrm{ml}$, porque se ha demostrado que hasta esta cifra se mantiene la calidad del producto. Cuando el proceso de ordeño, manipulación y almacenamiento se realiza en malas condiciones, el contenido bacteriano puede aumentar hasta varios millones por ml de leche, Schlimme y Buchheim, (2002) recomiendan que, para evitar esta situación se deben tener en cuenta los siguientes aspectos:

- Uso de sistemas apropiados de recolección, almacenamiento y conservación de la leche en finca.

- Higienización de las instalaciones, equipos de ordeño, tanques de almacenamiento y cantinas.

- Aplicación de los conceptos y métodos de la medicina preventiva en el hato lechero.

- Respeto de los tiempos de retiro de los medicamentos utilizados para el tratamiento de los animales.

- Capacitación permanente del personal sobre los aspectos relacionados con el mejoramiento de la calidad.

- La infraestructura de frío en la finca, como a lo largo de toda la cadena, es una variable importante en la conservación de la calidad de la leche. El 
establecimiento de tanques de enfriamiento no solo ayuda a esta labor, sino que optimiza el ordeño y la recolección de la leche por parte de las industrias.

\section{ORDEÑO Y CALIDAD DE LECHE}

Como se ha analizado, existen factores intrínsecos del sistema de producción que afectan la calidad de la leche, dentro de los cuales se destacan los relacionados con el animal (estado fisiológico, edad, curva de lactancia y raza) y otros relativos al sistema de alimentación, higiene y limpieza de utensilios, equipos, capacitación y rutina de ordeño. Dada la importancia de este último factor, especialmente para obtener una leche de buena calidad higiénica, se ha dedicado un aparte para el estudio de esta relación (Granda y Almanza, 2005).

La rutina de ordeño se inicia en el momento que el animal es llevado al sitio destinado para tal fin y finaliza con el almacenamiento de la leche en cantinas o tanques de enfriamiento. Incluye procesos secuenciales y continuos, necesarios para que se pueda obtener leche de buena calidad, los cuales pueden ser susceptibles de adaptación según el sistema de ordeño, disponibilidad de recursos físicos, tipo de ganado y características del recurso humano, por eso no es posible formular una rutina única para todas las fincas, sino que es necesario seguir unas pautas para realizar un ordeño adecuado. Inicialmente, los estímulos externos en el ordeño como son el ordeñador, el sitio y el lavado de pezones, generan una respuesta hormonal que promueve la secreción de oxitocina. Esta hormona permite la bajada de la leche en un tiempo aproximado de 4 a 7 minutos, tiempo durante el cual se debe ordeñar. La preparación pre-ordeño es un balance entre la rapidez (eficiencia) y la realización de los pasos requeridos para limpiar la ubre y estimular la bajada de la leche. El lugar de ordeño y sus condiciones influyen directamente tanto en la manipulación y recolección del producto como en su calidad higiénica y sanitaria. Los puntos básicos para un ordeño adecuado son: despunte, lavado, pre-sellado y secado de pezones; ordeñar siempre pezones secos y limpios, verificación del correcto funcionamiento del equipo de ordeño, 
disponibilidad de utensilios necesarios y aseo de las manos de operarios (Cortez y Martínez, 2000).

\section{HIGIENE DE UTENSILIOS Y EQUIPO DE ORDEÑO}

Algunos factores ligados a la contaminación de la leche en su recolección y almacenamiento son la calidad del agua, el procedimiento de lavado y desinfección de cantinas, y el tipo de jabón utilizado, adicional al lavado y mantenimiento de equipo (unidades y tanque de frío). La contaminación se da por microorganismos que provienen de la piel de los pezones, manos del ordeñador, pezoneras, agua, aire y en general de todo el ambiente que rodea el sitio de ordeño. La limpieza se inicia con el prelavado a $35-45^{\circ} \mathrm{C}$, que remueve los residuos de leche del equipo de ordeño y lo prepara para una mejor acción de las soluciones limpiadoras. Luego se lava con un producto clorado que ayuda a remover las proteínas, uno alcalino que ayuda a remover la grasa y un agente complejo (EDTA) que previene la formación de depósitos de sal dependiendo de la dureza del agua. Posteriormente se enjuaga con agua y ácido $35-45^{\circ} \mathrm{C}$, el cual neutraliza los residuos de cloro y detergentes alcalinos, prolonga la vida útil de las partes de caucho, previene la formación de depósitos minerales en la leche y elimina las bacterias. Por último, se hace el enjuague, preferiblemente con agua tibia $25-30^{\circ} \mathrm{C}$ con el fin de secar el equipo más rápido. Antes de reutilizar el equipo, se recomienda aplicar una solución sanitaria de hipoclorito (200 mg por litro de agua ó 200 ppm) para reducir el número de bacterias. Otro aspecto importante en la recolección es el filtrado y almacenamiento de la leche después del ordeño, actividad que consiste en separar de la leche aquellos residuos sólidos que la hayan contaminado durante el proceso. Para llevar a cabo esta operación se deben usar filtros de papel desechable o tela de lienzo (Granda y Almanza, 2005).

\section{MANEJO SANITARIO DEL HATO}

La experiencia realizada en la hacienda "Palo Negro" ubicada en la vereda "El Destino" en la localidad de Usme en el departamento de Cundinamarca, a 3.200 
msnm, con una temperatura promedio de $12^{\circ} \mathrm{C}$, se basó principalmente en la capacitación del personal y en la implementación de las buenas prácticas ganaderas (BPG) propuestas por el Instituto Agropecuario Colombiano (ICA), mediante la resolución 616 del 2006; con el fin de promover el mejoramiento de la calidad de la leche y a su vez el precio de pago por calidad.

Esta finca tiene un hato de 160 vacas lecheras Holstein puro, cuyo alimento básico son las gramíneas: raigrass (Lolium sp), falsa poa (Holcus lanatus), azul orchoro (Dactylis glomerata) y leguminosas: trébol rojo (Trifolium pratense) y blanco (Trifolium repens) (Fotografía 1). La producción promedio diaria del hato es 16 litros de leche/día/vaca; se suministra un kilo de suplemento concentrado/cinco litros de leche producida.

\section{Certificación de predio libre de brucelosis y tuberculosis}

a. Toma de muestras de sangre en la totalidad de los animales del hato.

b. Conservación, embalaje y envió de muestras al laboratorio del ICA, para determinación de brucelosis y tuberculosis.

Prueba de tuberculina en pliegue caudal. Se tomaron muestras de sangre en la totalidad de los animales del hato, bajo completas condiciones asépticas con tubos vacutainer y jeringas estériles. El área de la piel sobre la vena se lavó y se desinfecto con algodón y alcohol, evitando el contacto de las manos u otros objetos con el área desinfectada. La cantidad de sangre tomada fue $5 \mathrm{ml}$, se envió al laboratorio debidamente refrigerada y adicionada con un anticoagulante estéril. Las muestras fueron enviadas al laboratorio del ICA, para determinación de brucelosis y tuberculosis.

Todas las muestras se refrigeraron para disminuir el crecimiento de especies facultativas, lo cual preserva la muestra durante 18-24 horas en climas fríos. Se identificaron las muestras con los siguientes datos: Nombre completo y dirección del propietario del animal; reseña del animal incluyendo especie, sexo, edad y 
raza; tipo de vacunas empleadas, número de animales vacunados, fecha de las vacunaciones. Los resultados para todas las vacas fueron negativos.

La prueba de tuberculina se basa en el hecho de que el animal tuberculoso es alérgico a las proteínas del Mycobacterium contenidas en la tuberculina que inyectada por vía intradérmica a un animal que no padece la enfermedad no produce efectos demostrables, pero en un animal tuberculoso, ocasiona o causa una reacción local caracterizada por inflamación y tumefacción del sitio inyectado. La dosis utilizada por vía intradérmica es de $0.1 \mathrm{ml}$ de tuberculina. El lugar de la inyección se examina para observar la inflamación característica $72 \pm 6$ horas después de la inyección. La prueba de tuberculina se realizó en el pliegue ano caudal y los criterios de interpretación son: menos de $3 \mathrm{~mm}$ : negativo, de 3 a 5 $\mathrm{mm}$ : sospechoso y 5 ó mayor de $5 \mathrm{~mm}$ : positivo. El $100 \%$ de los animales, cuyas muestras fueron analizadas, dio un reporte negativo.

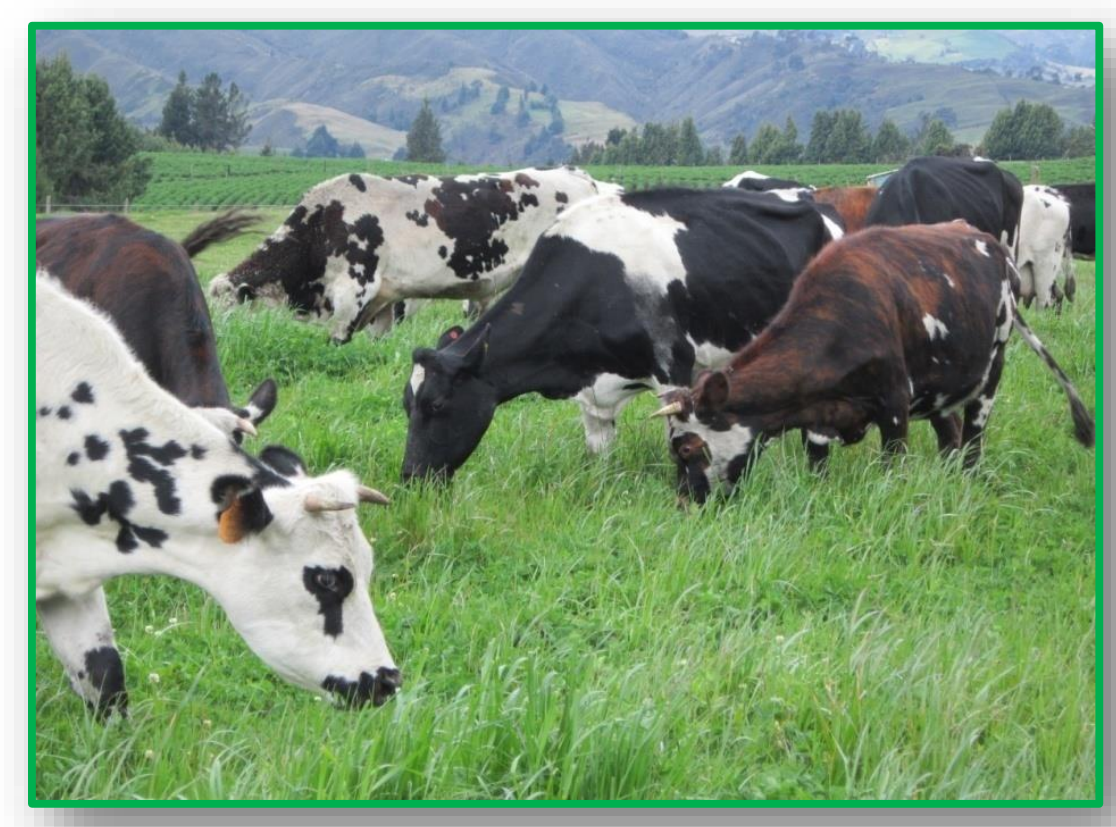

Fotografía 1. La alimentación básica es principalmente con pasto raygrass.

Con estos resultados se pudo iniciar el proceso de "Certificación de predio libre de brucelosis y tuberculosis", el cual debe tener seguimiento mediante la implementación de protocolos sanitarios. 


\section{Reducción del recuento de células somáticas}

Se identificaron animales que presentaron mastitis clínica o subclínica mediante la realización del test mastitis california (CMT). Con base en los resultados encontrados en los chequeos de CMT, se realizaron las medidas correctivas como: tratamiento de casos clínicos, retiro de leche de animales afectados con mastitis clínica o subclínica grado 3 y 4 , además se descartaron animales con persistencia en la presentación de la enfermedad, revisión y mantenimiento mínimo del equipo de ordeño mensualmente.

Para tomar las muestras de leche para realizar el test mastitis california (CMT), se desecharon dos chorros de leche de cada cuarto de la ubre. En cada uno de los depósitos de la paleta se agregó la leche y se añadió reactivo, luego se mezcló a través de movimientos circulares y suaves evitando revolver el contenido de los diferentes compartimientos. Antes de iniciar las buenas prácticas ganaderas (BPG) a una muestra de 40 vacas se les realizó el CMT. Del 100\%, el 36,96\% estaban afectados los cuatro cuartos, el $17.4 \%$ tres cuartos son positivos, el $21.7 \%$ dos cuartos son positivos, el $2.7 \%$ un cuarto es positivo y el $21.2 \%$ de las vacas dieron negativo a esta prueba. Dando como resultado general en el hato con 160 vacas en producción que un $78.8 \%$ tienen mastitis con algún grado de severidad. (Gráfica 1).

Después de seis meses de aplicación de BPG, se les repitió a una muestra de 40 vacas el CMT. Del $100 \%$ el $39.2 \%$ están afectados los cuatro cuartos, lo que indica que se incrementó en 2,2 unidades porcentuales (UP), a pesar de que se elevaron estas cifras, el efecto de la aplicación de las BPG se observó en los siguientes resultados: el $12.1 \%$ de los animales, los tres cuartos son positivos y el $2.4 \%$ dos cuartos son positivos, lo que indica que las unidades porcentuales disminuyeron en estos casos de mastitis en: $5.3 \%$ y $19.3 \%$, respectivamente. No fue igual el resultado, cuando el $4.8 \%$ de las vacas únicamente uno de sus cuartos fue positivo y el $41.4 \%$ dieron negativo al CMT, incrementado en 2.1 y $20.2 \%$ para estos dos casos dando como resultado que el $58.5 \%$ de las vacas tienen mastitis con algún grado de severidad (Fotografía 2 y Gráfica 2). 


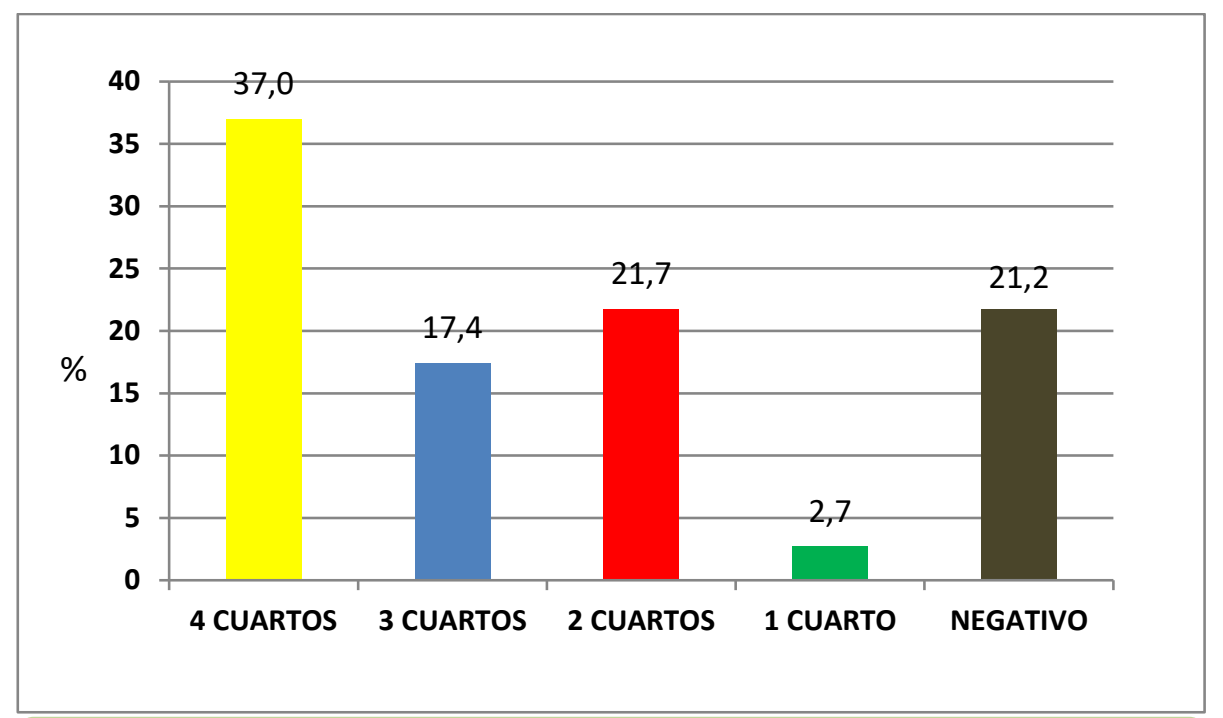

Gráfica 1. Porcentaje de incidencia de mastitis antes de aplicar buenas prácticas

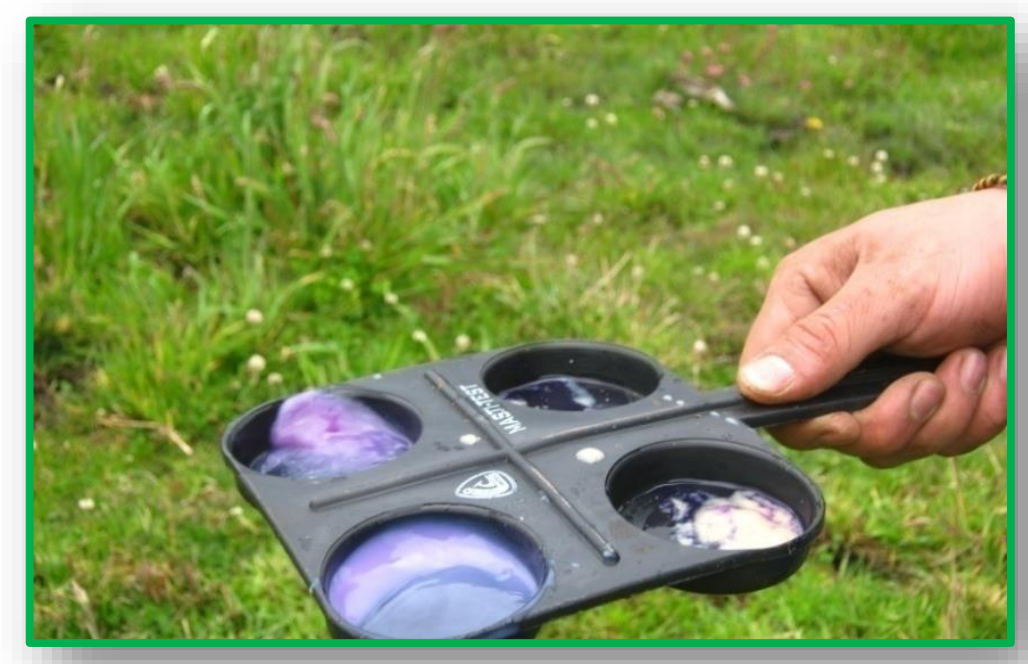

Fotografía 2. Prueba de california mastitis test para los cuatro cuartos de la ubre

De lo anterior se deduce que el problema de mastitis no solamente se puede controlar, sino que se puede erradicar de un hato estableciendo protocolos de buenas prácticas (Granda y Almanza, 2005). Como se aumentaron los casos de animales afectados los cuatro cuartos, se inició un proceso de descarte de manera gradual para hacer los respectivos reemplazos con vacas sanas, de esta manera se incrementaría su número, dando un mayor porcentaje de negativas a esta 
enfermedad. Como complemento a estas actividades también se vienen realizado las medidas correctivas: tratamiento de las vacas afectadas clínica y sub clínicamente y el retiro de leche que producen estas vacas para mantener la calidad de producto.

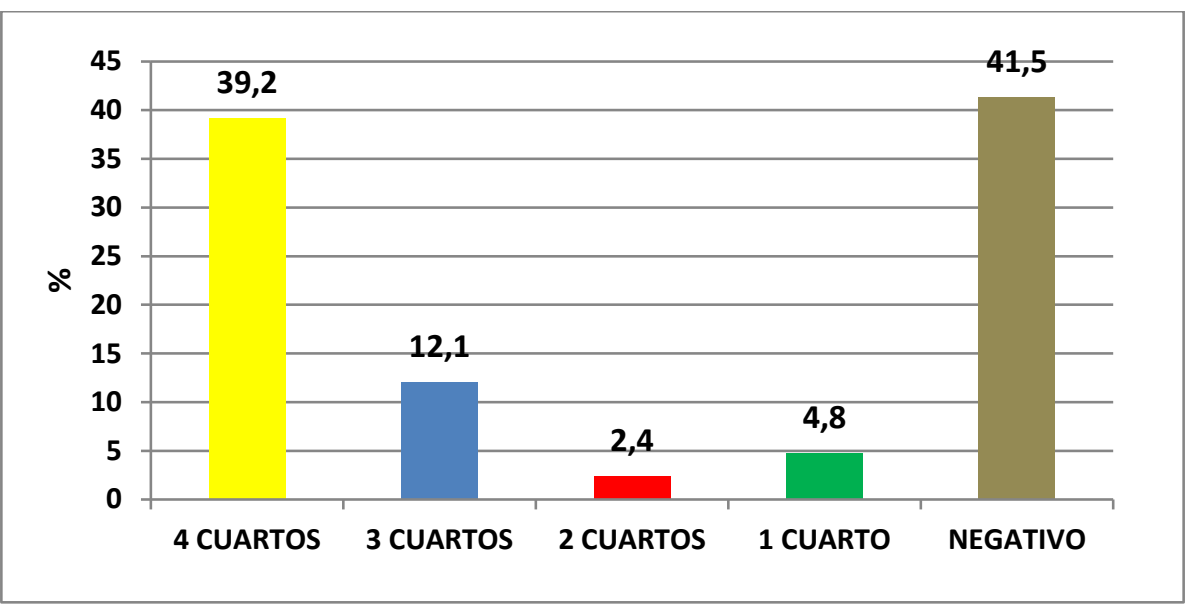

Gráfica 2. Porcentaje de incidencia de mastitis después de aplicar las buenas prácticas ganaderas

\section{Disminución de las Unidades Formadoras de Colonias}

a. Establecimiento de protocolos de lavado y desinfección del equipo de ordeño y tanque de enfriamiento de leche.

b. Capacitación del personal de la finca sobre el manejo y aplicación de protocolo para la rutina de ordeño mecánico.

c. Revisión y verificación semanal del cumplimiento de los protocolos.

d. Seguimiento bacteriológico semanal de la calidad de la leche en tanque, determinado el número de UFC/ml, en un Laboratorio de control calidad.

Se consideró que existe una relación directa entre la calidad de la leche y la higiene de los utensilios que se usan diariamente en el ordeño (cantinas, cepillos, baldes, equipo y sus componentes), además de la calidad del agua con que se realiza el lavado de los anteriores; es de suma importancia que se realice adecuadamente la limpieza. 
Los pasos del protocolo de limpieza de los equipos y elementos utilizados en el ordeño son:

a. Prelavado: Remueve los residuos de leche del equipo de ordeño y lo prepara para una mejor acción de las soluciones limpiadoras (deslechado con agua fría)

b. Lavado (detergente alcalino): Un producto clorado ayuda a remover las proteínas, el alcalino a remover la grasa y un agente complejo (EDTA) previene la formación de depósitos de sal dependiendo de la dureza del agua (Desengrasante neutro $100 \mathrm{ml} x$ $20 \mathrm{~L}$ de agua caliente $\left(50-75^{\circ} \mathrm{C}\right), 3$ veces por pezonera).

c. Enjuague con ácido: Neutraliza los residuos de cloro y detergentes alcalinos, prolonga la vida útil de las partes de caucho, previene la formación de depósitos minerales en la leche y elimina las bacterias. (Detergente ácido $100 \mathrm{ml}$ × $20 \mathrm{~L}$ de agua fría, dos veces por pezonera).

\section{Enjuague con agua}

a. Sanidad: Antes de reutilizar el equipo, se le debe lavar con una solución sanitaria de hipoclorito (200 mg por litro de agua o 200 ppm), lo cual reduce el número de bacterias (hipoclorito $80 \mathrm{ml} / 20 \mathrm{~L}$ de agua fría, 1 vez por pezonera). Para el lavado de tanque de enfriamiento se hizo de la siguiente manera: prelavado, lavado con agua fría y jabón/tres veces, luego lavado con detergente neutro 100 $\mathrm{ml} / 20 \mathrm{~L}$ de $\mathrm{H}_{2} \mathrm{O}$ y finalmente con hipoclorito $80 \mathrm{ml} / 20 \mathrm{~L}$ de agua una vez. El protocolo para la rutina de ordeño mecánico fue socializado con el personal de la finca (Tabla1).

Como reporta Rodríguez, (2007) que el recuento de UFC debe ser menor de 25.000 células por $\mathrm{ml}$ de leche para mantener la calidad del producto, en el caso de finca "Palo Negro" el recuento inicial fue de $62.500 \mathrm{UFC} / \mathrm{ml}$, el cual se considera alto, indicando que la calidad de la leche se puede disminuir. Al aplicar las buenas prácticas de manejo, limpieza de equipos materiales, desde el primer 
mes se observó el efecto en la disminución y actualmente, el hato se encuentra en 11.680 UFC/ml debido a la aplicación de estos protocolos en el proceso de ordeño (Gráfica 3).

Tabla 1. Protocolo para la rutina de ordeño

Desplazamiento al sitio de ordeño: se fijaron la hora de ordeño y también se trató en lo posible evitar situaciones que afecten la tranquilidad de los animales antes del ordeño. La adrenalina inhibe la acción de la oxitocina, dificultando la bajada de la leche.

Suministro de concentrado: la cantidad depende de la producción de cada vaca, por cada 5 litros de leche $1 \mathrm{~kg}$ de concentrado.

Despunte de pezones: consiste en colocar los dos o tres primeros chorros en un recipiente de contraste para determinar la posible incidencia de mastitis. Igualmente, se realiza con el fin de eliminar microorganismos de la cisterna del pezón y generar la bajada de la leche.

Presellado con solución yodada: Se sumergen los pezones en una sustancia desinfectante, permitiendo que actúe durante 20 a 30 segundos. Al aplicar este producto no es necesario lavar con agua. Se realiza para desinfectar los pezones antes del ordeño.

Secado con papel: se realiza antes de comenzar el ordeño utilizando un cuadro de papel desechable para cada pezón. Ello con el fin de estimular la bajada de la leche, retirar los remanentes del desinfectante aplicado y ordeñar pezones sin ningún tipo de humedad.

Sellado con solución yodada después del ordeño: evita la entrada de microorganismos por el esfínter del pezón, el cual permanece abierto cuando termina el ordeño.

Manejo de pastoreo: Se utiliza el sistema de cuerda, por medio de la cual se raciona el pasto, esta se mueve tres veces al día para que exista una adecuada disponibilidad de pasto.

Según Schlimme y Buchheim, (2002) los valores recomendados de recuento células somáticas (RCS) tienen que ser menores de 400.000/ml de leche (almacenada en cantina), inicialmente el hato "Palo Negro" tenía un recuento de de 2’371.000 RCS/ml, lo cual indicaba que las malas prácticas de ordeño e higiene estaban perjudicando el proceso. Una vez, iniciados los protocolos de desinfección de equipos y rutinas de ordeño que se están llevando a cabo satisfactoriamente, estos datos disminuyeron hasta 2’019.000 (Gráfica 4). 


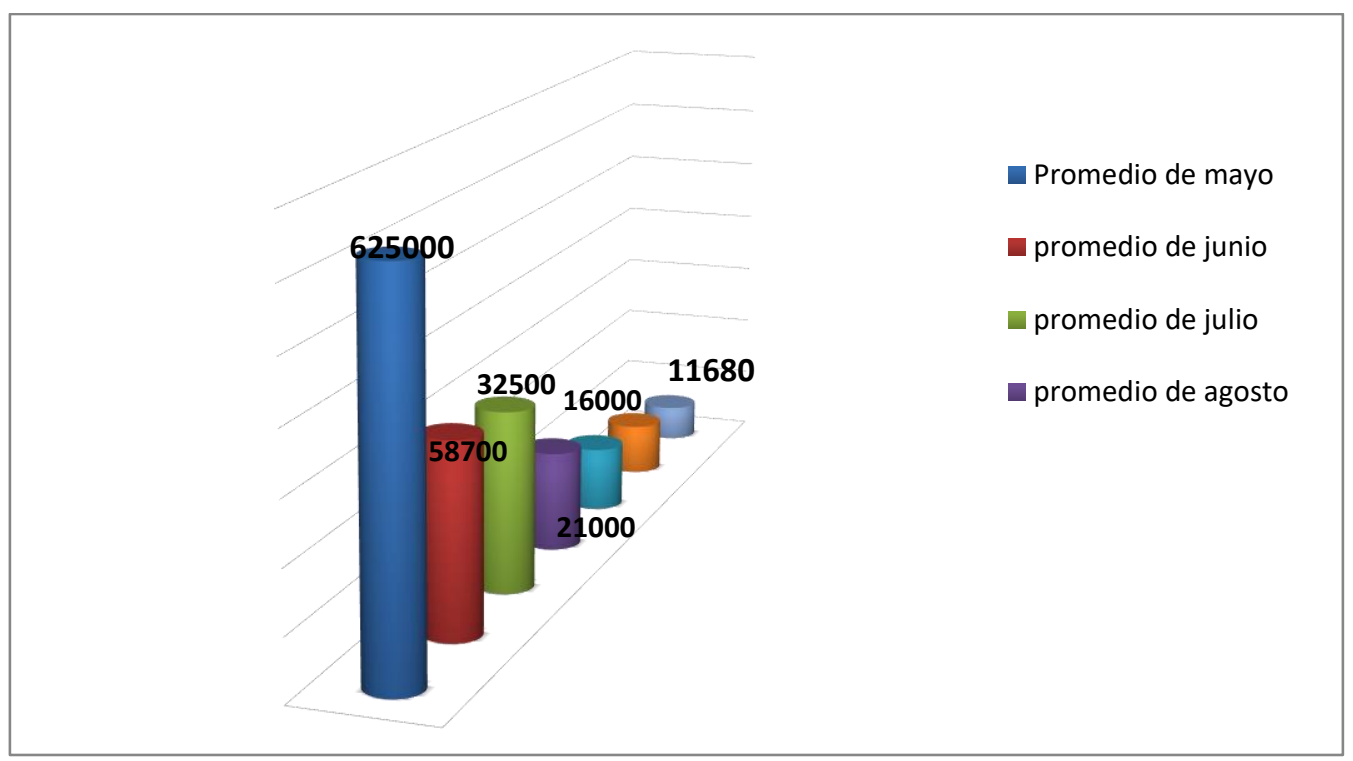

Gráfica 3. Efecto de la aplicación de buenas prácticas en disminuir unidades de formadoras colonias

\section{Bienestar animal}

a. Observación diaria de animales, verificando el suministro de alimento y agua suficiente para evitar estrés previo al ordeño.

b. Verificación del suministro de agua y alimento en las horas del ordeño, el cual se realiza a las 5:00 am y a las 2:00 p.m.

c. Vigilancia del personal en la aplicación de técnicas de bienestar animal.

d. Capacitación, donde se les explicaba a los operarios el buen trato a los animales, aspectos como: salud, presencia de dolor, cambios de conducta, alimentación, alojamiento, prevalencia de enfermedades multifactoriales y disminuciones de: consumo de alimentos, producción de leche, respuesta inmune y función reproductiva.

e. Divulgación en carteleras para enseñar a los operarios buenas prácticas de manejo de hato como: disminuir el estrés evitando movimientos bruscos y sonidos, movilizando el ganado con calma en pequeños grupos para evitar caídas y lesiones.

f. Revisión de las condiciones e instalaciones para asegurar el confort de las vacas y así establecer propuestas, con el propósito de suministrarles una mejor calidad de vida. 


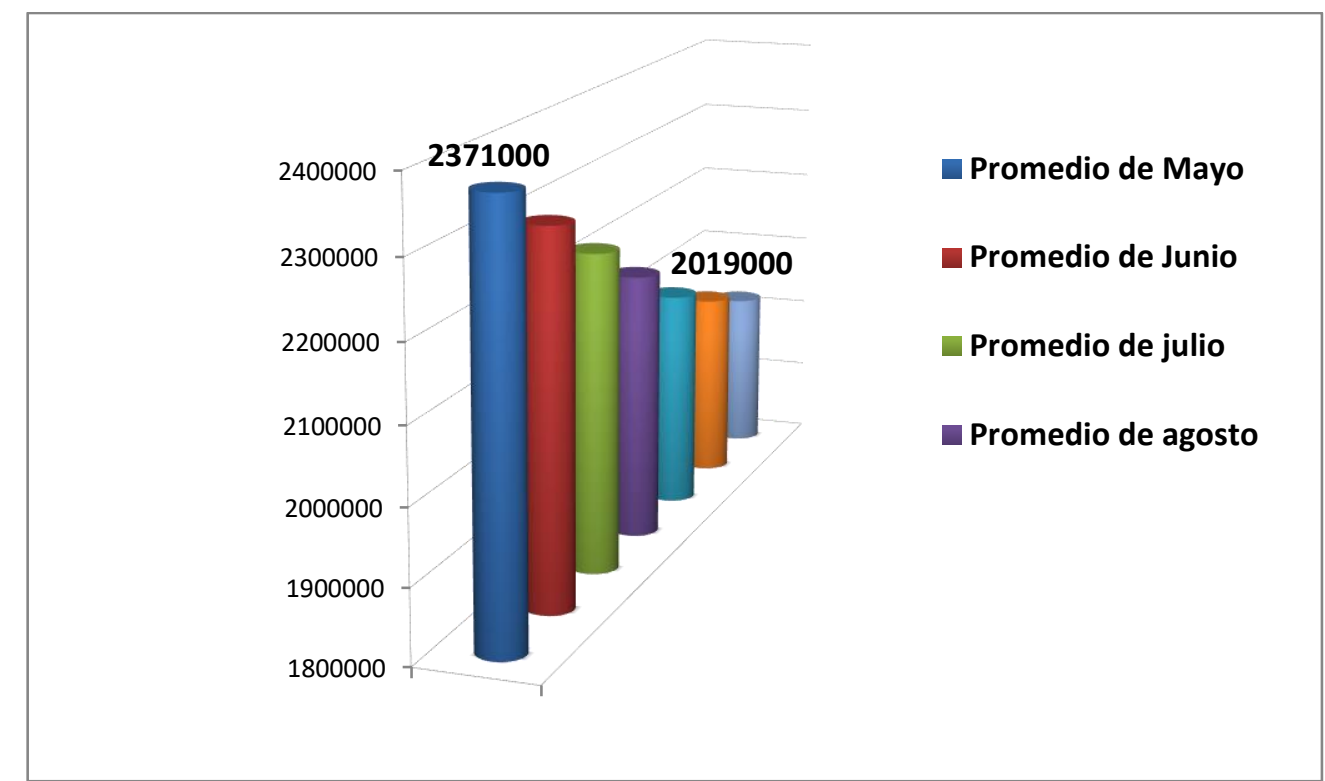

Gráfico 4. Valores del recuento de células somáticas / $\mathrm{ml}$ de leche

\section{Registros}

Cuando se empezó el trabajo en la finca existían algunos registros y otros se fueron implementando, para asegurar las buenas prácticas de manejo, para lo cual se comenzó con el inventario e identificación de animales, además se analizaron los registros de ingresos-egresos, compra-venta de animales, material genético e insumos, comparado contra el valor de pago de la leche.

Con la información recopilada se propuso sistematizar los registros individuales de cada vaca, producción leche/día, medicamentos, historia clínica, labores diarias, manejo reproductivo y de praderas (Tablas 2 a 7 ).

Tabla 2. Registro mensual de producción de leche / día

\begin{tabular}{|c|c|c|c|c|c|c|c|c|c|c|c|c|c|}
\hline \multicolumn{14}{|c|}{ MES } \\
\hline NÚMERO & \multirow[t]{2}{*}{ NOMBRE } & \multicolumn{3}{|c|}{1 SEMANA } & \multicolumn{3}{|c|}{2 SEMANA } & \multicolumn{3}{|c|}{3 SEMANA } & \multicolumn{3}{|c|}{4 SEMANA } \\
\hline & & AM & PM & TOTAL & AM & PM & TOTAL & $\begin{array}{c}\text { LTRS } \\
\text { AM }\end{array}$ & $\begin{array}{c}\text { LTRS } \\
\text { PM }\end{array}$ & TOTAL & $\begin{array}{c}\text { LTRS } \\
\text { AM }\end{array}$ & $\begin{array}{c}\text { LTRS } \\
\text { PM }\end{array}$ & TOTAL \\
\hline 1 & & & & & & & & & & & & & \\
\hline $2 \ldots \ldots \ldots \ldots n$ & & & & & & & & & & & & & \\
\hline TOTAL & & & & & & & & & & & & & \\
\hline PROMEDIO & & & & & & & & & & & & & \\
\hline
\end{tabular}


Tabla 3. Registro de manejo de praderas

\begin{tabular}{|l|c|c|c|c|c|}
\hline $\mathbf{N}^{\circ}$ Potrero & $\begin{array}{c}\text { Aforos, } \\
\text { producción } \\
\text { forraje } / \text { ha }\end{array}$ & $\begin{array}{c}\text { Días de } \\
\text { descanso } \\
\text { (fecha) }\end{array}$ & $\begin{array}{c}\text { Ocupación } \\
\text { (fecha) }\end{array}$ & $\begin{array}{c}\text { Grupo } \\
\text { Animales }\end{array}$ & Observaciones \\
\hline 1 & & & & & \\
\hline $2 \ldots \ldots \ldots \ldots \ldots n$ & & & & & \\
\hline Total & & & & & \\
\hline
\end{tabular}

Tabla 4. Control mensual de compra de alimentos

\begin{tabular}{|l|c|c|c|c|}
\hline \multicolumn{5}{|c|}{ Mes: } \\
\hline Materia Prima & Lote & Fecha compra & Valor unid. & Valor total \\
\hline & & & & \\
\hline & & & & \\
\hline Encargado: & & & \\
\hline Observaciones:
\end{tabular}

Tabla 5. Registro de suministro de medicamentos

\begin{tabular}{|c|c|c|c|c|c|c|c|}
\hline $\begin{array}{c}\text { No } \\
\text { Animal }\end{array}$ & $\begin{array}{c}\text { Fecha } \\
\text { Adm. }\end{array}$ & $\begin{array}{c}\text { Hora } \\
\text { Adm. }\end{array}$ & $\begin{array}{c}\text { Dosis } \\
\text { Adm. }\end{array}$ & $\begin{array}{c}\text { Vía } \\
\text { Adm. }\end{array}$ & Producto & $\begin{array}{c}\text { Registro } \\
\text { ICA }\end{array}$ & № Lote \\
\hline & & & & & & & \\
\hline & & & & & & & \\
\hline & & & & & & & \\
\hline
\end{tabular}

Tabla 6. Registro de palpaciones

\begin{tabular}{|l|l|l|}
\hline NOMBRE & ESTADO & TRATAMIENTO \\
\hline & & \\
\hline & & \\
\hline
\end{tabular}


Tabla 7. Registro intervalos parto - concepción

\begin{tabular}{|c|c|}
\hline NOMBRE & DIAS ABIERTOS \\
\hline ALFARO & 139 \\
\hline AMPARITO & 162 \\
\hline ASTA & 225 \\
\hline BANDOLERA & 26 \\
\hline BOQUINCHE & 32 \\
\hline
\end{tabular}

Tabla 8. Relación ingresos y egresos

\begin{tabular}{|l|l|l|l|}
\hline \multicolumn{1}{|c|}{ DETALLE } & $\begin{array}{c}\text { LITROS DE } \\
\text { LECHE }\end{array}$ & $\begin{array}{c}\text { PRECIO X } \\
\text { LITRO }\end{array}$ & $\begin{array}{c}\text { VALOR } \\
\text { TOTAL }\end{array}$ \\
\hline & & & \\
\hline INGRESOS & & & \\
\hline VENTA DE LECHE & & & \\
\hline OTROS & & & \\
\hline TOTAL INGRESOS & & & \\
\hline EGRESOS & & & \\
\hline COSTOS VARIABLES & & & \\
\hline COSTOS FIJOS & & & \\
\hline & & & \\
\hline UTILIDAD O PERDIDA & & & \\
\hline
\end{tabular}

\section{CONCLUSIONES Y RECOMENDACIONES}

Con la aplicación de buenas prácticas ganaderas disminuyó de manera gradual en seis meses la incidencia de mastitis en las vacas de la finca "Palo Negra" de 78.8 a $58.5 \%$, lo cual indica que 34 vacas de las 160 respondieron a los tratamientos veterinarios, los cuales fueron aplicados rigurosamente. Igual sucedió en las unidades formadoras de colonias y en el recuento de células somáticas las cuales disminuyeron en seis meses de 625.000 Vs 11680 y 2’371.000 vs 2’019.000.

Con base en los resultados de los chequeos de test mastitis california, se recomienda seguir con estos protocolos de manera estricta, para que el problema, no solamente se pueda controlar sino en el futuro erradicar la mastitis del hato. 
Se sugiere realizar proceso de descarte de manera gradual para hacer los respectivos reemplazos con vacas sanas, de esta manera incrementar el número de animales sanos, lo que beneficiara la calidad del producto final. La implementación de un sistema de registros es importante para el control y la administración de la hacienda.

El bienestar animal es el punto de equilibrio del estado físico y mental, generando una calidad de vida óptima para los animales, es importante recordar constantemente a los operarios que el buen manejo del ganado es el primer paso para obtener un producto de calidad.

Realizar cultivo y antibiograma de una muestra de leche del tanque para identificar el patógeno que está produciendo la mastitis y a que antibiótico es sensible esta bacteria, en base al resultado elegir el antibiótico para el tratamiento y secado de las vacas afectadas.

\section{REFERENCIAS BIBLIOGRÁFICAS}

1. Anda. Administración y calidad. Editorial Limusa. México. 192 p. 2007.

2. Blood D., Radostits O.M. Medicina veterinaria. Séptima edición. Vol. 1. Madrid, España: Interamericana McGraw Hill, 1992. p. 729-742.

3. Chesterton, N. Bienestar animal en las fincas lecheras. En: Congreso Panamericano de la Leche (10, C.R., abril, 2008). Memorias. Costa Rica, El Congreso. 2008.

4. Cortes H., Martínez I. Relación entre las prácticas de ordeño de los hatos lecheros del norte antioqueño con la calidad de la leche cruda. Tesis de grado. Bogotá: Universidad Nacional de Colombia. 2008.

5. Cordero, L; Quiroz, J; Vicente, C.M. Exploración clínica del bovino. Heredia, C.R, Editorial Fundación Universidad Nacional. 2005.

6. Granda H., Almanza F. Rutina de ordeño para la obtención de leche de excelente calidad. Cartilla de instrucción ANALAC. Ed. Promedios. Bogotá. 2005.

7. Ministerio de Agricultura y Desarrollo Rural - IICA. Acuerdo de Competitividad de la Cadena Láctea Colombiana. Bogotá. 98 p. 2007.

8. Ministerio de Protección Social (MPS). Decreto 616 del 2006.

9. Novoa C. Consideraciones sobre calidad de la leche. En: Seminario sobre fármaco-terapia de la vaca lactante, mastitis y calidad de leche. Memorias. Universidad Nacional de Colombia. Bogotá. 2005.

10. Ramos R, Pabón M, Carulla J. Factores nutricionales y no nutricionales que determinan la composición de la leche. Revista de Medicina Veterinaria y Zootecnia. XLVI (2). 2006. 
11. Rodríguez G. La Mastitis Bovina y el Potencial para su Control en la Sabana de Bogotá. Colombia. Informe Técnico No 2. Proyecto Colombo-Alemán. Bogotá: ICA-GTZ: 2007.

12. Schlimme E, Buchheim W. La leche y sus componentes, propiedades químicas y físicas. Editorial Acribia. Zaragoza, España. 121 p. 2006. 